\title{
Ileal and colonic epithelial metabolism in quiescent ulcerative colitis: increased glutamine metabolism in distal colon but no defect in butyrate metabolism
}

\author{
I A Finnie, B A Taylor, J M Rhodes
}

\begin{abstract}
Previous studies have shown that butyrate is an important energy source for the distal colon, and that its metabolism may be defective in ulcerative colitis (UC). A similar metabolic defect in the ileum might account for the occurrence of 'pouchitis' in UC patients after colectomy. A method has been developed that allows the measurement of metabolism in ileocolonoscopic biopsy specimens, and this has been used to assess butyrate and glutamine metabolism in quiescent UC and controls. Preliminary experiments showed optimal metabolism of butyrate at $1 \mathrm{mmol} / 1$. In controls glutamine metabolism was greater in the ascending (mean (SD)) $(4.9(3.2) \mathrm{nmol} / \mathrm{h} / \mu \mathrm{g}$ protein) than in the descending colon $(1.4$ $(0.7))(p<0.05$, Mann-Whitney U test), but butyrate metabolism was similar in the two regions (ascending $62.6(\mathbf{4 4 . 2})$, descending $51 \cdot 5(32 \cdot 0))$. Consequently ratios of butyrate/ glutamine metabolism were higher in the descending colon $(20.6(14.3))$ than in the ascending colon $(14.3(9.6))(p<0.05)$. In UC, rates of butyrate metabolism were similar in the ascending $(92.5(58.3) \mathrm{nmol} / \mathrm{h} / \mu \mathrm{g}$ protein) and descending (93.3 (115)) colon, and these were not significantly different from controls. In UC, glutamine metabolism was similar in the ascending $(6.2(7 \cdot 7) \mathrm{nmol} / \mathrm{h} / \mu \mathrm{g}$ protein) and descending colon $(7.8(7.9))$; the metabolism in the descending colon was significantly greater than in controls $(\mathbf{p}<0.01)$. Butyrate (135 (56) $\mathrm{nmol} / \mathrm{h} / \mu \mathrm{g}$ protein) and glutamine $(24 \cdot 1(16 \cdot 2))$ metabolism in the ileum in UC, were not significantly different from control values (butyrate 111 (57), glutamine $15 \cdot 5(15 \cdot 6))$. These results confirm that there is regional variation of nutrient utilisation throughout the colon, but they do not support the hypothesis that UC is caused by a deficiency of butyrate metabolism.

(Gut 1993; 34: 1552-1558)
\end{abstract}

There is strong evidence that colitis can result from impaired mucosal metabolism. It has been shown that the colonic epithelium obtains much of its energy supply from fatty acids, particularly butyrate, which are present in the colonic lumen as a result of fermentation of carbohydrates by bacteria. Colitis occurs in the defunctioned colon after diversion of the faecal flow and subsides when the faecal flow is replaced. ${ }^{12}$ The occurrence of colitis in animals that are vitamin deficient ${ }^{3}$ or that are treated with inhibitors of fatty acid metabolism ${ }^{4}$ supports the theory that fatty acid metabolism is vital to the well being of the colonic epithelium. Colitis, which is histologically similar to ulcerative colitis, has also been described in association with pellagra. ${ }^{5}$

How the various forms of nutritional colitis relate to ulcerative colitis (UC) is uncertain, but studies have suggested that metabolism of the short chain fatty acid butyrate is impaired in UC. ${ }^{6-9}$ In these studies, in common with many others, it has not been possible to discover if the change was a primary defect or merely a secondary effect of the disease process.

The frequency of 'pouchitis' in ulcerative colitis patients who have colectomy and pouch construction contrasts with the apparent rarity of pouchitis in patients who have the same operation for familial polyposis. ${ }^{10}$ This implies a potential abnormality of the ileal mucosa in ulcerative colitis that is not evident when the ileum and colon are in normal continuity, with the possible exception of 'backwash ileitis'. In view of this it seems appropriate to study mucosal metabolism in ileal as well as colonic mucosa in UC patients and controls in the expectation that any abnormalities that could be detected in the histologically normal ileum of ulcerative colitis patients would be unlikely to be secondary phenomena.

A further problem with the interpretation of some previous studies of mucosal metabolism ${ }^{6} 7$ has been concern that the procedure used for isolating a pure epithelial cell population from resected bowel specimens may itself have introduced artefacts, and that these artefactual changes might well have been different in the inflamed colitic tissue from those in the histologically normal colon.

This paper describes a technique that allows metabolism of nutrients to be assessed in whole epithelial biopsy specimens, and this technique has been used to assess the metabolism of butyrate and glutamine by ileal and colonic biopsy specimens from patients with idiopathic ulcerative colitis and controls.

\section{Methods}

MUCOSAL BIOPSY SPECIMENS

All specimens were taken using Olympus FB $13 \mathrm{U}$ colonscopy forceps at routine colonoscopy, except in two patients in whom ileal specimens were obtained through an ileostomy with the same forceps. Bowel preparation in all colonoscopy patients was similar, consisting of Picolax, two sachets on the day before colonoscopy and clear fluids for 48 hours. All patients gave written informed consent, and the studies were 
approved by the ethical committee of the Royal Liverpool University Hospital.

\section{SUBJECTS}

\section{Colonic studies}

Ascending and descending colonic biopsy specimens were taken from 12 patients with longstanding quiescent ulcerative colitis who were being examined as part of a programme to screen for dysplasia/malignancy, and from 12 patients who acted as controls, who did not have ulcerative colitis. The final diagnosis of the control patients was sporadic colonic polyps $(n=4)$, diverticular disease (3), haemorrhoids (2), unexplained anaemia (1), carcinoma (1), and irritable bowel syndrome (1). All specimens in these control patients were taken from a site at least $5 \mathrm{~cm}$ from any macroscopic abnormality, and adjacent mucosal specimens, which were normal on histological examination were obtained in all.

The mean duration of colitis was 12 years (range 6-18). The median age of UC patients was $43(28-65)$, which was not significantly different from the control median $48(18-68)(p=0 \cdot 21$, Mann-Whitney U test). Sex ratios were similar, but none of the UC patients smoked whereas six controls were current smokers. All the UC patients were taking regular 5-amino salicylic acid preparations, but none was taking any form of corticosteroid.

\section{Ileal studies}

Terminal ileal biopsy specimens were taken at ileocolonoscopy (four patients) for patients with longstanding quiescent ulcerative colitis and by the ileostomy of two patients who had a colectomy for UC (histological reports state that 2 and $4 \mathrm{~cm}$ of ileum had been resected with the colectomy). Ileal specimens were taken from eight patients who did not have UC and who acted as controls. One of the UC patients who had had an ileostomy had mild non-specific inflammatory changes histologically (but no symptoms), but the ileal mucosa was histologically normal in all other cases. The mean duration of ulcerative colitis was 14 years, and these patients were having colonoscopy to exclude dysplasia/malignancy, except the patients with ileostomies who gave informed consent for ileoscopy specifically for this study. The median ages were similar (UC patients 48, controls 51). The final diagnosis in control patients was diverticular disease $(n=3)$, colonic cancer (1), unexplained anaemia (1), and irritable bowel syndrome (3). Three controls smoked, none of the UC patients did so, and all UC patients except the two with ileostomies were taking regular 5-amino salicylic acid preparations.

\section{MUCOSAL METABOLISM}

The method that Veerkamp et al" devised to study fatty acid metabolism in skeletal muscle was adapted to study intestinal mucosal metabolism. After removal, mucosal biopsy specimens were placed in ice cold pregassed
Krebs-Henseleit buffer containing $11 \mathrm{mM}$ glucose, and transported within 10 minutes to the laboratory. Each specimen was divided by scalpel into approximately 10 pieces per specimen (each piece approximately $1 \mathrm{mg}$ ), and then placed in a glass scintillation vial in $1 \mathrm{ml}$ KrebsHenseleit containing $11 \mathrm{mM}$ glucose to which had been added either $1 \mu \mathrm{Ci}$ sodium $\left[1-{ }^{14} \mathrm{C}\right]$ butyrate and $1 \mathrm{mM}$ sodium butyrate, or $1 \mu \mathrm{Ci} \mathrm{L}$ $\left[{ }^{14} \mathrm{C}(\mathrm{U})\right]$ glutamine and $1 \mathrm{mM}$ glutamine. An Eppendorf reaction tube was suspended above the culture medium, the vial was gassed with $95 \% \mathrm{O}_{2} / 5 \% \mathrm{CO}_{2}$ and closed with a rubber seal (see Fig 1). The vials were cultured for two hours at $37^{\circ} \mathrm{C}$ in a shaking water bath (Grant Instruments, Cambridge, UK) set at 120 oscillations per minute. At the end of the culture period $0.25 \mathrm{ml} 10 \%$ perchloric acid was injected into the culture medium to stop the reaction, and $0.5 \mathrm{ml}$ of a solution of $66 \%$ ethane $1,2 \mathrm{diol} / 33 \%$ ethanolamine was injected into the Eppendorf tube to absorb ${ }^{14} \mathrm{CO}_{2}$. The vials were kept at $4^{\circ} \mathrm{C}$ for 90 minutes to allow equilibration, after which the Eppendorf reaction tubes were removed and placed in $10 \mathrm{ml}$ scintillant, which was a mixture of $4 \mathrm{~g} / 1$ Omnifluor in 2:1 toluene/methanol. After vigorous shaking, these were then counted in a Beckman scintillation counter. All counts were corrected by subtraction of counts for ${ }^{14} \mathrm{C}$ liberated in control vials without specimens.

Total biopsy specimens protein content was estimated at the end of the incubation period using a Lowry method ${ }^{12}$ after ultrasonication ( $4 \times 15$ second bursts with an MSE (MSE Instruments, Crawley, UK) ultrasonicator at maximum power setting).

Results were expressed as nmol substrate metabolised per hour, after correcting for specific radioactivity of the substrate and number of ${ }^{14} \mathrm{C}$ atoms per molecule. For each patient, each assay was performed in duplicate at each site studied and the mean of the results calculated.

Comparisons of the metabolism between different sites in the same patient, and the same

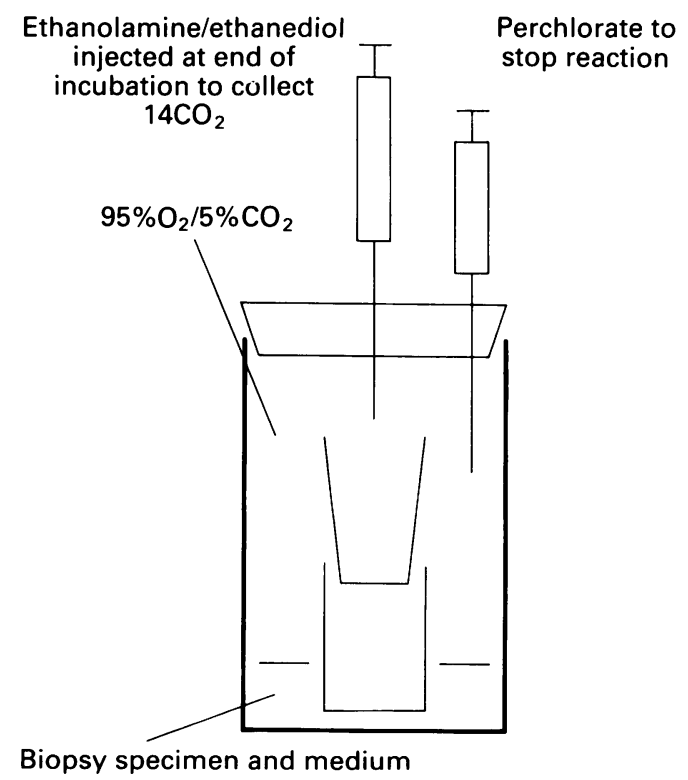

Figure 1: Apparatus for measurement of metabolism by colonic biopsy specimens. For detailed description see methods section. 
Figure 2: Rate of metabolism of butyrate by colonic biopsies. The rate of metabolism of ${ }^{14} \mathrm{C}$ butyrate to ${ }^{14} \mathrm{CO}_{2}$ by colonoscopic biopsy specimens taken from a resected colon was found to be linear for at least three hours. Metabolism is measured as number of nmol ${ }^{14} \mathrm{CO}_{2}$ produced from sodium $\left[1-{ }^{14} \mathrm{C}\right]$ butyrate per ug biopsy protein. Similar time course experiments for glutamine confirmed that rate of metabolism was linear for the duration of the culture period (results in text).
Figure 3: Metabolism of butyrate at different concentrations. Conversion of butyrate to $\mathrm{CO}_{2}$ was greater at a concentration of $1 \mathrm{mM}$ than at $10 \mathrm{mM}$ $(p<0.05)$, or at $0.067 \mathrm{mM}$ $(p<0.01)$, but did not differ significantly from $5 \mathrm{mM}(p=$ 0.33) (Kruskal-Wallis).

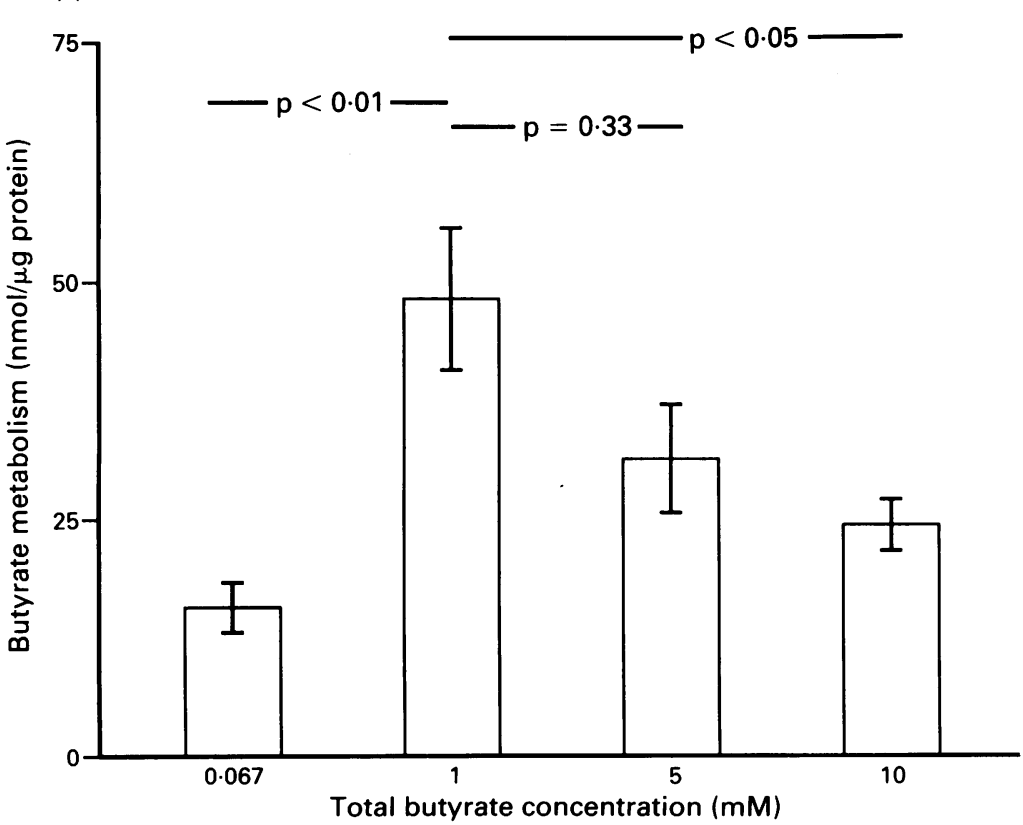
concentrations of unlabelled sodium butyrate. propria lymphocytes to measured metabolism we obtained peripheral blood lymphocytes from the heparinised blood of a patient having colonoscopy for polyp surveillance with centrifugation in Lymphoprep (Flow Laboratories, Rickmansworth, UK). Lymphocytes $\left(12.8 \times 10^{6}\right)$ were prepared from $10 \mathrm{ml}$ heparinised blood. Viability was measured using trypan blue exclusion and was found to be $>\mathbf{9 5 \%}$ both before and after two hours culture. Five $200 \mu$ l aliquots representing $2.56 \times 10^{6}$ lymphocytes were each placed in Krebs-Henseleit with a colonoscopic biopsy specimen taken from the same patient and metabolism measured as below for mucosal biopsy specimens. The results were compared with those obtained when culturing colonic specimens in the absence of the lymphocyte preparation.

sites in UC patients and controls were analysed using a non-parametric (Mann-Whitney U) test. (95\% confidence intervals $(95 \% \mathrm{CI})$ for difference between means are quoted where appropriate.)

\section{VALIDATION EXPERIMENTS}

Small pieces (about $3 \times 2 \mathrm{~cm}$ ) of resected colon were obtained within 30 minutes of removal from patients having colectomy for cancer or diverticular disease, and placed in ice cold Krebs-Henseleit buffer at $\mathrm{pH} 7 \cdot 4$ (Sigma Chemical Co, Poole, UK) containing $11 \cdot 1 \mathrm{mM}$ glucose, gentamicin $100 \mu \mathrm{g} / \mathrm{ml}$ and nystatin 60 $\mu / \mathrm{ml}$, which was pregassed with $95 \% \mathrm{O}_{2} / 5 \%$ $\mathrm{CO}_{2}$. The tissue studied was taken at least $5 \mathrm{~cm}$ distant from any macroscopic disease. The mucosal surface was then pinned out and biopsied with colonoscopy biopsy forceps. The specimens were than analysed using the method described previously for mucosal metabolism.

A series of experiments was performed to detect the optimal concentration of butyrate in the culture system. For these experiments specimens were cultured in the same concentration of radiolabelled sodium butyrate but with different

To assess the potential contribution of lamina

Attempts were made to measure the relative contribution to the overall metabolism of mucosa, lamina propria, and muscularis layers. By gently scraping the mucosa and lamina propria from a small piece of resected colon with a scalpel blade and biopsying the tissue below, it was possible to compare metabolism of mucosal biopsy specimens with that of submucosal specimens (histologically shown to contain connective tissue and muscularis)

A further series of experiments was performed to assess whether colonic bacteria could contribute to measured metabolism. This was necessary in case there were different adherent bacteria on the mucosal surface in disease and controls, and for these experiments faecal fluid was aspirated at colonoscopy and added in $\mathbf{1 0 0}$ $\mu \mathrm{l}$ aliquots to a specimen in the culture system. Control experiments were performed adding 100 ul Krebs-Henseleit. In addition, experiments were conducted with, and without $100 \mu \mathrm{g} / \mathrm{ml}$ gentamicin and $60 \mu \mathrm{g} / \mathrm{ml}$ nystatin in the KrebsHenseleit.

\section{Results}

VALIDATION EXPERIMENTS

The rates of metabolism of butyrate (Fig 2) and of glutamine were found to be roughly linear for at least three hours. For butyrate oxidation the rate in the first hour was (mean (SD)) 110.8 $(16.5) \mathrm{nmol} / \mu \mathrm{g}$ protein, over two hours 85.8 $(11 \cdot 1) \mathrm{nmol} / \mathrm{h} / \mu \mathrm{g}$ protein, and over three hours $90.3(8.8)(p<0.0001$ for linearity test using grouped regression analysis (Arcus Pro-II). For glutamine the rate of metabolism in the first hour was $5 \cdot 1(1 \cdot 1) \mathrm{nmol} / \mu \mathrm{g}$ protein, $4 \cdot 6(2 \cdot 2) \mathrm{nmol} / \mathrm{h} /$ $\mu \mathrm{g}$ protein over two hours, and $4 \cdot 3(1 \cdot 0)$ over three hours $(\mathrm{p}<0.0001$ for linearity test). Metabolism of butyrate was optimal at $1 \mathrm{mM}$ (Fig 3) and for this reason we decided to use $1 \mathrm{mM}$ butyrate for the remainder of the study.

Reproducibility was checked with six biopsy specimens from adjacent sites in a single patient and coefficient of variation was found to be $12 \%$ for butyrate metabolism expressed per $\mu \mathrm{g}$ protein per hour and $18 \%$ for glutamine metabolism.

The mean overall coefficient of variation assessed by comparison of paried biopsy specimens was $20 \%$ for butyrate metabolism and $23 \%$ for glutamine metabolism. 
TABLE I Metabolism of glutamine and butyrate by mucosal biopsy specimens

\begin{tabular}{lll}
\hline & $\begin{array}{l}\text { Controls } \\
(n=12)\end{array}$ & $\begin{array}{l}\text { Ulcerative } \\
\text { colitis } \\
(n=12)\end{array}$ \\
\hline Ascending colon butyrate & $62 \cdot 6(44 \cdot 2)$ & $92 \cdot 5(58 \cdot 3)$ \\
Ascending colon glutamine & $4 \cdot 9(3 \cdot 2)^{\star}$ & $6 \cdot 2(7 \cdot 7)$ \\
Ascending colon butyrate/glutamine & $14 \cdot 3(9 \cdot 6) \dagger$ & $14 \cdot 6(9 \cdot 25)$ \\
Descending colon butyrate & $51 \cdot 5(32)$ & $93 \cdot 3(115)$ \\
Descending colon glutamine & $1 \cdot 4(0 \cdot 7)^{\star} \ddagger$ & $7 \cdot 8(7 \cdot 9) \ddagger$ \\
Descending colon butyrate/glutamine & $20 \cdot 6(14 \cdot 3) \dagger$ & $15 \cdot 9(15 \cdot 6)$ \\
\hline
\end{tabular}

Mean figures for metabolism ( $\mathrm{nmol} / \mu \mathrm{g}$ protein/h) of each nutrien are given with standard deviation in brackets. Values with same superscript are significantly different at $\mathrm{p}<0.05\left({ }^{\star} \dagger\right)$ or $\mathrm{p}<0.01(\ddagger)$ using Mann-Whitney U test.

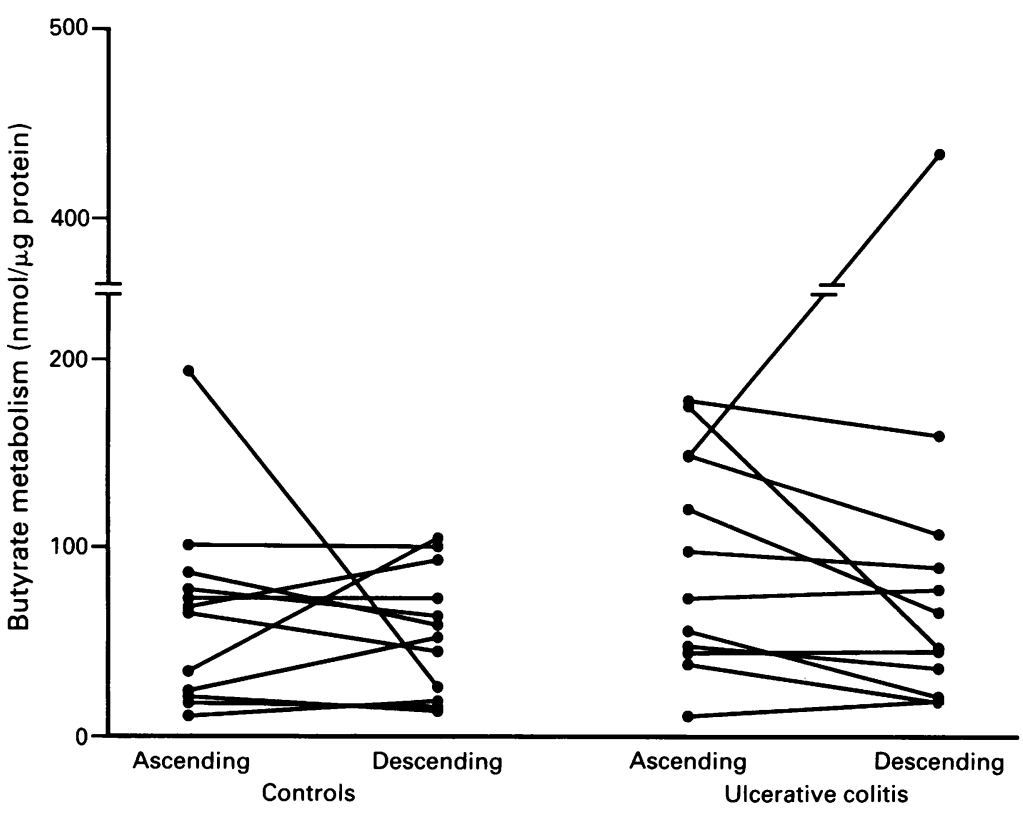

Figure 4: Metabolism of butyrate (colon). Butyrate metabolism was similar in the ascending colon and descending colon of controls. Metabolism in ulcerative colitis patients did not differ significantly.
Submucosal specimens metabolised comparatively little butyrate $(5.6 \quad(3.2) \mathrm{nmol} / \mu \mathrm{g}$ protein $/ \mathrm{h})($ mean $(\mathrm{SD}), \mathrm{n}=5)$ and glutamine $(0 \cdot 2$ $(0 \cdot 2), n=5)$ compared with mucosal specimens (butyrate $66 \cdot 2(13 \cdot 2), \mathrm{n}=5, \mathrm{p}<0 \cdot 01$, glutamine $4 \cdot 2(0 \cdot 6), \mathrm{n}=5, \mathrm{p}<0 \cdot 01)$

The addition of peripheral blood lymphocytes had no significant effect on butyrate metabolism (biopsy specimen with lymphocytes $49 \cdot 2(12 \cdot 3)$ $\mathrm{nmol} / \mu \mathrm{g}$ protein/h, without lymphocytes $52 \cdot 2$ $(10 \cdot 2)$ ) (mean (SD) of five experiments) $(95 \%$ $\mathrm{CI}=-22 \cdot 4$ to $24 \cdot 6)$, or glutamine metabolism (biopsy specimen with lymphocytes $5 \cdot 5(2 \cdot 2)$, without lymphocytes $4 \cdot 5(1 \cdot 6))(95 \% \mathrm{CI}=-2 \cdot 6$ to $3 \cdot 2$ ).

The addition of $100 \mu$ faecal fluid to a biopsy specimen in culture did not significantly affect metabolism of butyrate (biopsy specimen+ faecal fluid $49.7(10 \cdot 1) \mathrm{nmol} / \mu \mathrm{g}$ protein $/ \mathrm{h}$, biopsy specimen + Krebs-Henseleit $52 \cdot 2(5 \cdot 8)$ ) (mean (SD), five experiments per group) $(95 \% \mathrm{CI}=-18 \cdot 1$ to $22 \cdot 5)$ or glutamine (biopsy specimen + faecal fluid $5 \cdot 7(1 \cdot 1)$, biopsy specimen + Krebs-Henseleit $6.8(2.2))(95 \% \mathrm{CI}=-3.8$ to $2 \cdot 2)$. The addition of gentamicin and nystatin to the Krebs-Henseleit buffer had no significant effect on metabolism of butyrate by colonic biopsy specimens (with antibiotics $56(10 \cdot 3)$, without antibiotics $53 \cdot 4(7 \cdot 9))(95 \% \mathrm{CI}=-16 \cdot 2$ to $21 \cdot 2$ ).

Incubation with sodium $\left[1-{ }^{14} \mathrm{C}\right]$ butyrate in the absence of mucosal biopsy specimens led to an increase in scintillation in the Eppendorf vial of $512(35)$ (mean (SD), $n=6$ ) disintegrations per minute (DPM) above background, which may have been because of the volatility of the butyrate. This was small $(<3 \%)$ in comparison with the radioactivity produced by substrate metabolism in the presence of mucosal biopsy specimens (range 24000-115000 DPM) Incubation with ${ }^{14} \mathrm{C}$ glutamine in the absence of mucosal biopsy specimens gave results that were less than $5 \%$ of the values obtained when a biopsy specimen was present.

\section{COLONIC MUCOSAL METABOLISM (Table I)}

\section{Controls}

No significant difference was found in the rate of metabolism of butyrate by biopsy specimens taken from the ascending and descending colon (Fig 4). Glutamine metabolism was significantly greater in the ascending than in descending colon $(\mathrm{p}<0.05$, Mann-Whitney U test) (Fig 5). Ratios of butyrate/glutamine metabolism were significantly lower $(p<0.05)$ in the ascending than in the descending colon (Fig 6).

\section{Ulcerative colitis}

Butyrate metabolism was similar in ascending and descending colon, and these values were not significantly different from those found in controls (Fig 4). In ulcerative colitis glutamine metabolism was significantly greater in the descending colon than in controls $(p<0.01)$ and there was no significant difference between glutamine metabolism in the proximal and distal colon.
Figure 5: Metabolism of glutamine (colon). In controls, glutamine metabolism was significantly greater in the ascending than in the descending colon $(p<0 \cdot 05$, Mann-Whitney $U$ test $)$. In comparison, ulcerative colitis patients had significantly greater metabolism in the descending colon $(p<0.01)$, but values in the ascending colon were not significantly different. 


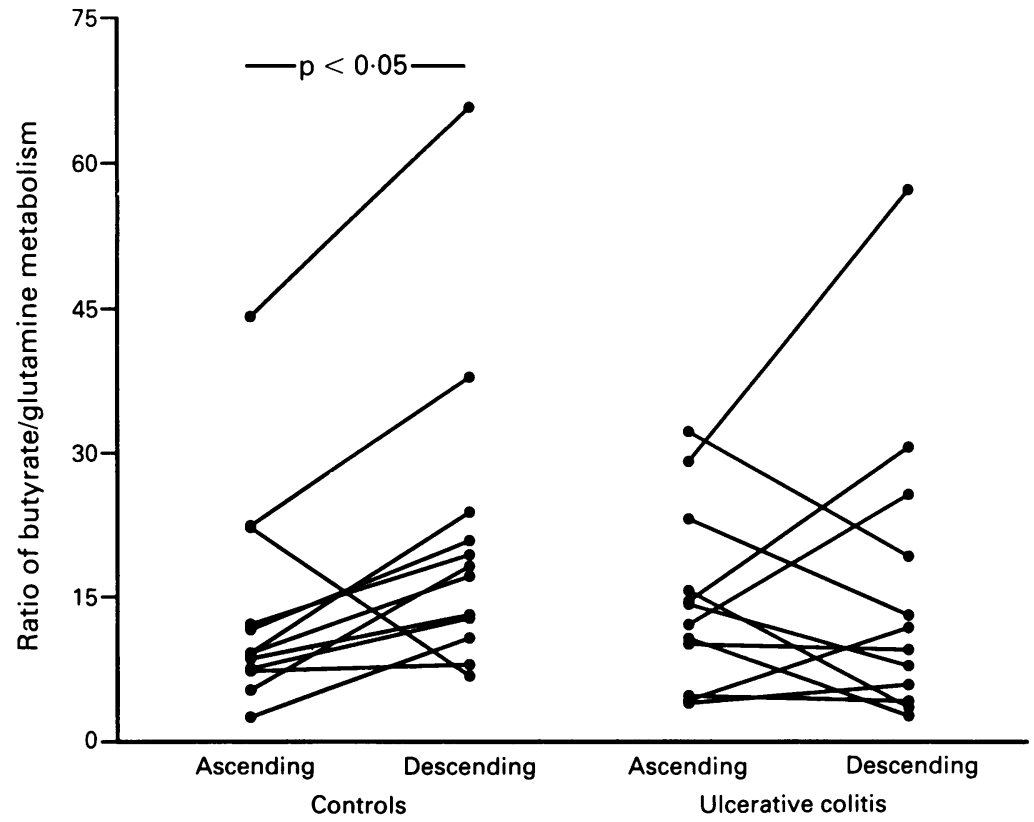

Figure 6: Butyratel glutamine ratio (colon). In controls, the ratio of butyrate/glutamine metabolism was significantly higher in the descending than in the ascending colon $(p<0 \cdot 05)$. In ulcerative colitis patients, this relation was lost, and there was no significant difference between controls and ulcerative colitis patients in either site.

The mean ratio of butyrate/glutamine metabolism in the descending colon was greater in controls than in UC, but this did not quite reach significance $(p=0.09)$. Ratios for the ascending colon were similar.
TABLE II Metabolism of glutamine and butyrate by ileal mucosa

\begin{tabular}{llc}
\hline & $\begin{array}{l}\text { Controls } \\
(n=8)\end{array}$ & $\begin{array}{l}\text { Ulcerative } \\
\text { colitis }(n=6)\end{array}$ \\
\hline Butyrate & $111(57)$ & $135(56)$ \\
Glutamine & $15 \cdot 5(15 \cdot 6)$ & $24 \cdot 1(16 \cdot 2)$ \\
Butyrate/glutamine & $13 \cdot 6(11 \cdot 2)$ & $11 \cdot 5(11 \cdot 1)$ \\
\hline
\end{tabular}

Mean figures (SD) for metabolism ( $\mathrm{nmol} / \mu \mathrm{g}$ protein $/ \mathrm{h}$ ) of each nutrient are given.

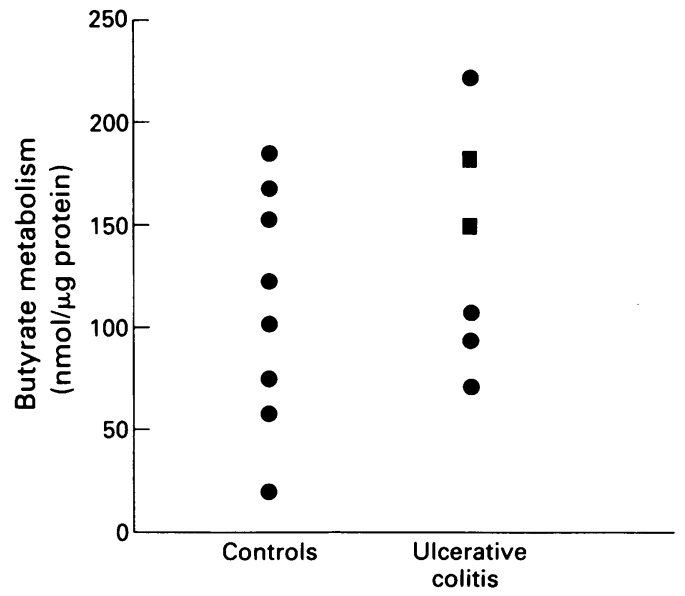

ILEAL MUCOSAL METABOLISM (Table II)

In controls the rate of butyrate metabolism in the ileum was significantly higher than in the ascending colon $(p<0.05)$, and although the mean rate of glutamine metabolism was also higher in the ileum this did not quite achieve statistical significance $(p=0.06)$. The ratios of butyrate/ glutamine metabolism were similar in the two regions. In UC the mean rate of butyrate metabolism was greater in the ileum than in the ascending colon, although the difference between the rates was not significant $(p=0.09)$; glutamine metabolism was significantly greater in the ileum than in the ascending colon in UC $(p<0.05)$. No significant difference was found between the rates of metabolism of butyrate or of glutamine by ileal biopsy specimens taken from UC patients compared with controls, and the ratios of butyrate/glutamine metabolism did not differ between UC patients and controls (Figs 7, 8 , and 9).

Each data point in Figs 4 to 9 represent the mean of two experiments.

Discussion

In this study mucosal metabolism of butyrate and glutamine in the terminal ileum, ascending colon, and descending colon have been measured in controls and patients with ulcerative colitis. In controls, we found similar rates of butyrate metabolism in the ascending and descending colon, but greater rates of glutamine metabolism in the proximal colon. Thus, although the ratio of butyrate:glutamine metabolism was greater in the normal distal colon this resulted from
Figure 7: Butyrate metabolism (ileum). Butyrate metabolism in ileal biopsy specimens taken at colonoscopy $(-)$ or through an ileostomy ([) was similar in controls and ulcerative colitis patients.

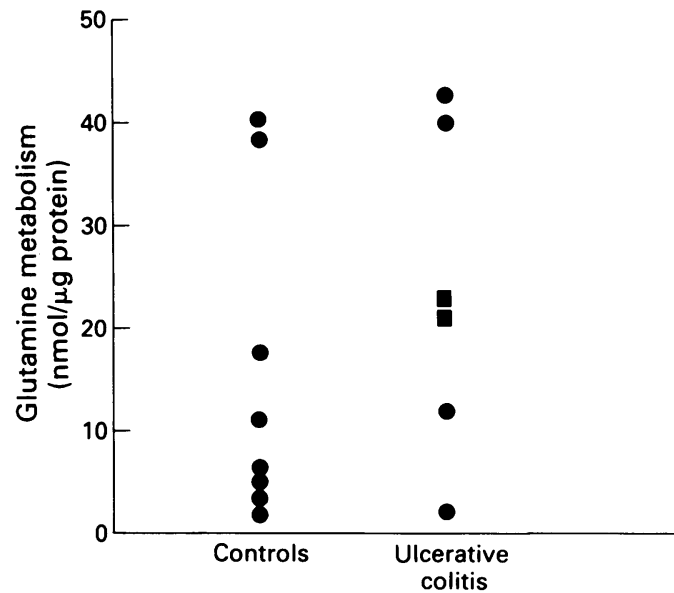

Figure 8: Glutamine metabolism (ileum). Ileal glutamine metabolism did not differ significantly between controls and ulcerative colitis patients.

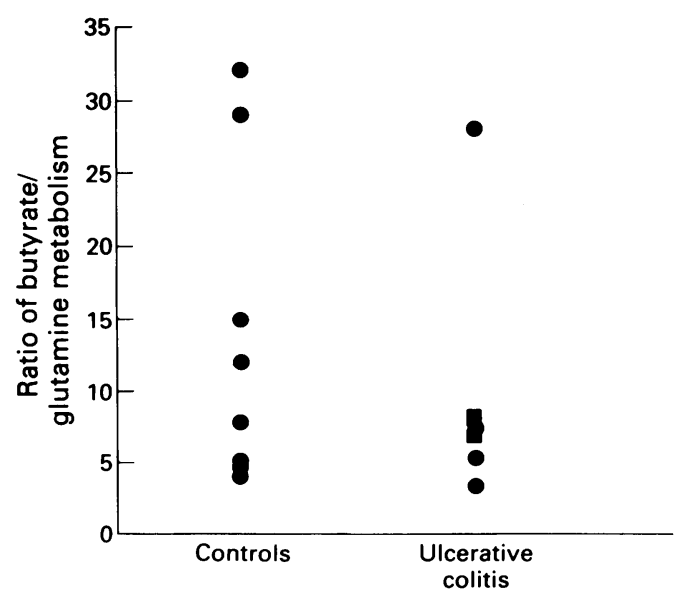

Figure 9: Butyrate/glutamine ratio (ileum). The ratio of butyratelglutamine metabolism in the ileum of controls and ulcerative colitis patients was similar. 
reduced glutamine metabolism rather than increased butyrate metabolism. Rates of butyrate metabolism in controls and ulcerative colitis patients were similar for all three regions studied, but glutamine metabolism was significantly greater in the descending colon in ulcerative colitis. This resulted in a ratio of butyrate/ glutamine metabolism that was slightly (but not significantly, $p=0.09$ ) lower in ulcerative colitis compared with controls.

It has been established that glutamine is an important food for many rapidly dividing cells, ${ }^{13}$ and the increased rate of glutamine utilisation in UC probably relates to the increased rate of proliferation seen in this condition. The higher rate of metabolism of glutamine in the ascending than in the descending colon in controls is in agreement with the findings of Roediger ${ }^{14}$ and indeed close examination of his work shows that the difference in the rates of butyrate metabolism in ascending and descending colon was in fact small compared with the difference between rates of glucose metabolism and oxygen consumption. Fleming et $a l^{15}$ have reported no difference in butyrate metabolism between caecal and colonic cells isolated from rats.

It is interesting that butyrate metabolism in controls was greater in the terminal ileum than in the ascending colon and this may suggest that the mucosa here is exposed to the products of bacterial fermentation.

The similar metabolism of butyrate in controls and in patients with ulcerative colitis, is in contrast with previous studies, ${ }^{67}$ where butyrate oxidation was impaired in mucosal cells isolated from quiescent and active ulcerative colitis. This discrepancy probably results from the different techniques used to measure metabolism. We have used a technique, whereby mucosal metabolism can be measured in mucosal biopsy specimens, and therefore patients in remission can easily be studied. In addition, our technique avoids potential damage to cells during the cell isolation procedure by EDTA and dithiothreitol. It also seems probable that cells from inflamed epithelium (colitis) will be more prone to toxicity from cytokines than will cells from control tissue and this may have introduced artefactual abnormalities in dispersed colitic cells. The fact that patients with active colitis were more affected than those with quiescent disease in Roediger's studies ${ }^{6}$ could reflect this. A further anxiety over the use of dispersed cells for metabolic studies comes from the finding that the metabolism of fatty acids entering intestinal mucosa from the lumen and plasma is different. ${ }^{16}$ Exposure to the surrounding solution of the parts of the cell membrane that are normally in apposition might well affect the metabolism within the cell. Two studies ${ }^{89}$ have reported defective butyrate metabolism in epithelial biopsy specimens (as opposed to isolated enterocytes) from patients with ulcerative colitis but these have so far been published only in abstract form. Chapman et $a l^{8}$ used a similar technique to the one described here, and found significantly lower rates of butyrate metabolism, and nonsignificant reductions in glutamine and glucose metabolism in UC. Their results on butyrate metabolism therefore concur with the findings of the dispersed cell experiments ${ }^{67}$ and are not in agreement with our findings. The lower rates of metabolism of glutamine and glucose, however, found in UC in that study are not in agreement with either our or Roediger' ${ }^{6}$ findings, so the implications of this report remain unclear. One possible reason for the difference between Chapman's and our results is that their experiments were all performed in the presence of $5 \mathrm{mM}$ glutamine ( $M$ Chapman, personal communication) whereas our experiments were carried out in the absence of glutamine. The study by Williams et al $^{9}$ reported no metabolism of either butyrate or glutamine by biopsy specimens taken from two UC patients, although there was no report on tissue viability. Some of the reported difference in rates of metabolism could relate to the severity of the underlying colitis. $^{6}$

One further possible explanation for the discrepancy between some of our and Roediger's findings could be that the methods of assessing metabolism were different. For example where he used production of ammonia, we have relied on production of $\mathrm{CO}_{2}$ as the measurement of glutamine metabolism. It is possible that the route of metabolism of substrates, rather than the rate of their metabolism, is different in the diseased state.

There are some potential disadvantages of using biopsy specimens as opposed to epithelial cell preparations for metabolic studies. It could be argued that different specimens could have different proportions of actively metabolising (mucosa) and inactive (lamina propria) tissue. For this reason we used a constant size of biopsy forceps throughout the study and reproducibility of the assays was satisfactory. Any error as a result of variation in the proportion of active and inactive tissue between patients (such as might result if one patient's mucosa was atrophic) should be alleviated by measuring glutamine metabolism in adjacent biopsy specimens and examining the ratio of butyrate/ glutamine metabolised. The validation experiments suggested that lymphocytes probably contribute little to overall measured metabolism. Binder $^{17}$ found an excess of 1000 cells $/ \mathrm{mm}^{2}$ lamina propria in mildly active UC compared with controls, and assuming specific gravity $=1$ and that lamina propria accounts for about half the weight of a biopsy specimen, the excess number of cells in lamina propria of a $10 \mathrm{mg}$ specimen $=150000$. Selby et $a l^{18}$ isolated an excess of $44 \times 10^{6}$ mononuclear cells/g UC mucosa, or 440000 per $10 \mathrm{mg}$ biopsy, so both these estimates are considerably smaller than the number of lymphocytes studied with each biopsy $\left(2 \cdot 56 \times 10^{6}\right)$.

One further effect worth considering is the bowel preparation before harvesting of the tissue. Ardawi and Newsholme ${ }^{19}$ have shown that starvation reduces the rate of metabolism of glutamine, but not that of ketone bodies by colonocytes. By avoiding variations in bowel preparation (apart from the two patients with ileostomies) any such effect due to a change in diet should be equivalent in the UC and control patients.

It was notable that butyrate metabolism was 
greatest at a concentration of $1 \mathrm{mM}$ with a fall off in metabolism at higher concentrations. Concentrations of $10-15 \mathrm{mM}$ are present in the colonic lumen, ${ }^{20-22}$ but separated cells and biopsy specimens might well react differently from an intact mucosal surface. Morita et $a l^{23}$ have reported toxic effects of sodium butyrate above $2 \mathrm{mM}$ in a colon cancer cell line and it may be that previous studies have used concentrations of butyrate that are higher than optimal.

Studies have suggested that both diversion colitis $^{1}$ and ulcerative colitis ${ }^{24}$ respond to rectally given short chain fatty acids, and recently a controlled trial of butyrate enemas in ulcerative colitis showed significant improvement in clinical and pathological parameters over placebo. ${ }^{25}$ Vernia and colleagues ${ }^{26}$ have shown reduced concentrations of butyrate in the faecal water of patients with ulcerative colitis, but not in Crohn's colitis. A reduced short chain fatty acid concentration has also been reported in pouch contents from patients with pouchitis compared with those without. ${ }^{27}$ The response of ulcerative colitis to butyrate administration suggests that the mucosa is able to utilise butyrate adequately, and makes it more plausible that the colitis results from a deficiency of, rather than an inability to metabolise, butyrate.

These studies show that mucosal metabolism can be assessed effectively using biopsy specimens without the need for epithelial cell purification. The increased metabolism of glutamine by the distal colon in ulcerative colitis seems probably to reflect a response to inflammation and consequent hyperplasia and is in keeping with evidence that respiratory chain enzymes are increased in ulcerative colitis. ${ }^{28}$ It seems unlikely from this work that ulcerative colitis is a result of a primary defect in butyrate metabolism.

Dr Finnie is supported by a grant from Mersey Regional Health Authority.

1 Harig JM, Soergel KH, Komorowski RA, Wood CM Treatment of diversion colitis with short-chain-fatty acid Treatment of diversion colitis with sho
irrigation. NEngl $\mathcal{M}$ Med 1989; 320: 23-8.

2 Korelitz BI, Cheskin LJ, Sohn N, Sommers N. Proctitis after faecal diversion in Chron's disease and its elimination with reanastomosis: implications for surgical management. Gastroenterology 1984; 87: 710-3

3 Wintrobe MM, Follis RH, Alcayaga R, Paulson M Humphreys S. Pantothenic acid deficiency in swine. Bull fohns Hopkins Hosp 1943; 73: 313-33.

4 Roediger WE, Nance S. Metabolic induction of experimenta ulcerative colitis by inhibition of fatty acid oxidation. $\mathrm{Br}$ Exp Pathol 1986; 67: 773-82.
5 Segal I, Tim LO, Demetriou A, Paterson A, Hale M, Lerios M. Rectal manifestations of pellagra. Int $\mathcal{F}$ Colorect Dis 1986 ; 1: $238-43$.

6 Roediger WEW. The colonic epithelium in ulcerative colitis: an energy deficiency disease. Lancet 1980; ii: 712-5.

7 Ireland A, Jewell DP. 5-aminosalicylic acid (5-ASA) has no effect on butyrate metabolism in human colonic epithelial cells. Gastroenterology 1989; 102: A 176.

8 Chapman MAS, Grahn MF, Hutton M, Rogers J, Williams NS. Failure of colonic mucosa to oxidise butyrate in NS. Failure of colonic mucosa to oxidise
ulcerative colitis [Abstract]. Gut 1992; 33: S40.

9 Williams NN, Brannigan A, Fitzpatrick JM, O'Connell PR. Glutamine and butyric acid metabolism measurement in biopsy specimens (ex-vivo): a method of assessing treatmen on inflammatory bowel conditions. Gastroenterology 1992 102: A713.

10 Madden MV, Farthing MJG, Nicholls RJ. Inflammation in ileal reservoirs: pouchitis. Gut $1990 ; 31: 247-9$.

11 Veerkamp JH, Van Moerkerk HTB, Glatz JFC, Van Hinsbergh VWM. Incomplete palmitate oxidation in cellfree systems of rat and human muscles. Biochim Biophys Acta 1983; 753: 399-410.

12 Lowry OH, Rosebrough NJ, Farr AL, Randall RJ. Protein determination with the Folin-phenol reagent. $f$ Biol Chem 1951; 193: 265-75.

13 Ardawi MSM, Newsholme EA. Metabolism in lymphocytes and its importance in the immune response. Essays Biochem 1985; $21: 1-44$

14 Roediger WEW. Role of anaerobic bacteria in the metabolic welfare of the colonic mucosa in man. Gut 1980; 21 : 793-8.

15 Fleming SE, Fitch MD, DeVries S, Liu ML, Kight C Nutrient utilisation by cells isolated from rat jejunum, cecum and colon. F Nutr 1991; 121: 869-78.

16 Gangl A, Ockner RK. Intestinal metabolism of plasma free fatty acids. Intracellular compartmentation and mechanism of control. $\mathcal{F}$ Clin Invest 1975; 55: 803-13.

17 Binder V. Cell density in lamina propria of the colon. A quantitative method applied to normal subjects and ulceraquantitative method applied to normal subjects and ulcera-

18 Selby WS, Janossy G, Bofill M, Jewell DP. Intestinal lymphocyte subpopulations in inflammatory bowel disease: an analysis by immunohistological and cell isolation techniques. Gut 1984; 23: 32-40.

19 Ardawi MSM, Newsholme EA. Fuel utilization in colonocytes of the rat. Biochem $\mathcal{F} 1985$; 231: 713-9.

20 Cummings JH, Hill MJ, Bone ES, Branch WJ, Jenkins DJA The effect of meat protein and dietary fiber on colonic function and metabolism. Part II. Bacterial metabolites in feces and urine. Am F Clin Nutr 1979; 32: 2094-101.

21 Rubinstein $R$, Howard AV, Wrong OM. In vivo dialysis of faeces as a method of stool analysis. IV. The organic anion component. Clin Sci 1969; 37: 549-64.

22 Cummings JH, Pomare EW, Branch WJ, Naylor LP, Macfarlane GT. Short chain fatty acids in human large Macfarlane GT. Short chain fatty acids in human large intestine,

23 Morita A, Tsao D, Kim YS. Effect of sodium butyrate in HRT-18, a human rectal cancer cell line. Cancer Res 1982; 42: 4540-5.

24 Breuer RI, Buto SK, Christ ML, Bean J, Vernia P, Paoluzi P et al. Rectal irrigation with short-chain fatty acids for distal ulcerative colitis. Preliminary report. Dig Dis Sci 1991; 36: $185-7$.

25 Scheppach W, Sommer H, Kirchner T, Paganelli G-M, Bartram P, Christl S, et al. Effect of butyrate enemas on the colonic mucosa in distal ulcerative colitis. Gastroenterology 1992; 103: 51-6.

26 Vernia P, Gnaediger A, Hauck W, Breuer RI. Organic anions and the diarrhea of inflammatory bowel disease. Dig Dis $S c i$ and the diarrhea

27 Clausen MR, Tvede M, Mortensen PB. Short-chain fatty acids in pouch contents from patients with and without pouchitis after ileal pouch-anal anastomosis. Gastroenterology 1992, 103: 1144-53.

28 Mayall T, Macpherson A, Bjarnason I, Forgacs I, Peters T Mitochondrial function of colonic epithelial cells in inflammatory bowel disease. Gut 1992; 33 (suppl 1): S24. 
Consequently, growing older, educational standard, and social habits could participate in atrophic gastritis but not in the same way as for the acquisition of $H$ pylori.

Microbiologie, Facu 垈é de Médecine, 1 place de Verdun, 59045 Lille Cedex, France

1 Mitchell HM, Lee A, Carrick J. Increased incidence of Campylobacter pylori infection in gastenter troenterologists: further evidence to support person-to-person transmission of Campy-
lobacter pylori. Scand $₹$ Gastroenterol 1989; 24: 396-400.

2 Bayerdorffer E, Oertel H, Lehn N, Kasper G, Mannes GA, Sauerbruch T, et al. Topographic association between active gastritis and Campylobacter pylori colonisation. $\mathcal{F}$ Clin Pathol 1989; 42: 834-9.

3 Heresbach D, Raoul JL, Bretagne JF, Minet J, Donio PY, Ramee MP, et al. Helicobacter pylori: a risk and severity factor of non-steroidal anti-inflammatory drug induced gastropathy. Gut 1992; 33: 1608-11.

\section{- \\ BOOK REVIEW}

Diseases of the Gut and Pancreas. Edited by J J Misiewicz, R E Pounder, C W Venables. 2nd ed. (Pp 1160; illustrated; f99.50.) Oxford: Blackwell Scientific, 1994.

The evolving relationship between a gastroenterologist who has acquired a new textbook can be compared with a car owner and his new car. Both objects look bright and new at the beginning. It is a different and interesting experience to 'get into them' but, quite soon, the novelty wears off. Occasionally, when they are particularly needed, either can let you down.

With textbooks, it is perhaps a little unfair to come to a hurried judgment on a first edition. Indeed, there may be a case for sparing detailed critical attention until the second edition has come along. If the textbook is not up to scratch, it will not actually reach a second edition but, by the time a revised version does hit the market, authors and editors will have had an opportunity to refine the product.

I had a copy of the first edition of this book and, judging by its rather osteoporotic spine, I seem to have used it quite a lot. It was certainly unique on my bookshelf in being the only substantial textbook of gastroenterology that could be easily held and read in the hand. Its length and breadth were barely larger than the original size of this journal (deceased 1989). The second edition has grown in length and breadth (about the dimensions of the modern Gut - 1990 onwards) and has slightly contracted in width. How good is this new model?

It is very much a textbook of clinical gastroenterology, as its title would imply. Furthermore, it is emphatically in a single volume, and I have to say it is my strong personal view that it is very much a frustration of modern life to have to read multi-author chapters in multi-editor texts that come in multiple volumes. The growth of knowledge is inexorable, but it is good to see this matched by editorial excellence, which make the book both readable and undaunting. For example, the whole of inflammatory bowel disease is covered in $\mathbf{9 0}$ pages with ulcerative and Crohn's disease, each having three chapters on their clinical features, medical management, and surgery respectively. I have not seen the clinical aspects of inflammatory bowel disease covered so well given this sort of space constraint, but there is necessarily some sacrifice of detail, particularly the pathogenesis (especially immunology) of these conditions. One accepts that a single volume will inevitably concentrate on the most clinically relevant areas but, since its first edition, there has been a really substantial expansion in the number of references for each chapter with almost all increasing by at least half and, in many cases, doubling.

The publisher has served the authors and editors really well. The various hierarchies of headings and subheadings are very easy on the eye. The figures and tables are beautifully produced and the $x$ rays are compellingly clear. As usual, black and white histology is disappointing and it seems curious that there are so many photographs of extremely thin naked people. Sadly, gastrointestinal disease may cause patients to become thin and I am not sure how much is gained from reminding us of this so visually.

Inevitably, any reviewer will find 'highs' and 'lows'. I have already mentioned my liking of the section on inflammatory bowe disease, but I also enjoyed the chapter on nutrition. The section entitled 'Colonic Polyps' was a little disappointing. This is surely an area of keen interest for gastroenterologists. The table of polyposis syndrome made no mention of hereditary non-polyposis colon cancer or Lynch syndrome. Perhaps a detailed discussion of molecular genetics was outside the scope of the book, but I think this most exciting area of gastrointestinal research could have merited a few lines. By contrast, the immunogenetics of coeliac disease is discussed but, in this otherwise very readable chapter, it is surprising to find no discussion of the widening spectrum of the condition.

This is an excellent book. It is written by practising clinicians for practising clinicians and, as such, is not surpassed.

IAN FORGACS

\section{NOTES}

\section{Sir Francis Avery Jones BSG Research Award 1995}

Applications are invited by the Education Committee of the British Society of Gastroenterology who will recommend to Council the recipient of the 1995 Award. Applications (fifteen copies) should include:

(1) A manuscript (2 A4 pages only) describing the work conducted.

(2) A bibliography of relevant personal publications.

(3) An outline of the proposed content of the lecture, including title.

(4) A written statement confirming that al or a substantial part of the work has been personally conducted in the United Kingdom or Eire.

Entrants must be 40 years or less on 31 December 1995 but need not be a member of the BSG. The recipient will be required to deliver a 40 minute lecture at the Spring meeting of the Society in 1995. Application (fifteen copies) should be made to: The Honorary Secretary, BSG, 3 St Andrews Place, London NW1 4LB by 1 December 1994

\section{Gastroenterology and liver disease}

The 20th anniversary of Annual Topics in Gastroenterology and Liver Disease will be held on 5-7 October 1994 in Baltimore Maryland, USA. Further information from: Program Coordinator, Johns Hopkins Medical Institutions, Office of Continuing Education, Turner Building, 720 Rutland Avenue, Baltimore, Maryland 21205, USA. Tel: 410 955-2959.

\section{Gastrointestinal motility}

The Eighth Biennial Meeting of the American Motility Society will be held on 20-23 October 1994 at Wintergreen Resort, Wintergreen, Virginia, USA. For further information contact the Office of Continuing Medical Education, Box 368, University of Virginia Health Sciences Center, Charlottesville, Virginia 22908, USA. Tel: 8049245310 .

\section{Liver diseases}

The American Association for the Study of Liver Diseases will hold a series of meetings during November 1994 in Chicago, USA. Further information on these meetings is available from: AASLD, Registration Manager, 6900 Grove Road, Thorofare, NJ 08086, USA. Tel: 6098481000 , extn 213 .

\section{Pancreatic diseases}

The Combined Meeting of the International Association of Pancreatology and American Pancreatic Association will be held on 2-4 November 1994 in Chicago, USA. Further information from: Linda Bakken, GI Unit 2-424, Mayo Clinic, 200 1st Street SW, Rochester, MN 55905, USA. Tel: 507255 4303; fax: 5072556318.

\section{Therapeutic endoscopy}

The Chinese University of Hong Kong and the Hong Kong Society of Digestive Endoscopy will hold the Ninth International Workshop on Therapeutic Endoscopy on 6-8 December 1994 in Hong Kong. Further information from: Dr Sydney Chung, Endoscopy Centre, The Chinese University of Hong Kong, Prince of Wales Hospital, Shatin, NT, Hong Kong. Tel: 852636 2233; fax: 8526350075 .

\section{Correction}

An authors' error occurred in the paper by $\mathrm{Dr}$ I A Finnie et al (Gut 1993; 34: 1552-8). The units of metabolism for butyrate and for glutamine throughout the paper should have been $\mathrm{nmol}$ substrate metabolised $/ \mathrm{h} / \mathrm{mg}$ protein and not, $\mathrm{nmol} / \mathrm{h} / \mu \mathrm{g}$ protein as stated. The ratios for butyrate/glutamine metabolism, the statistical analysis, and the conclusions remain unchanged. 